\title{
COMPLEXITY AND AGENT BASED MODELS IN THE POLICY PROCESS
}

\author{
Bridget Rosewell \\ Volterra Partners \\ 56-58 Putney High Street \\ London SW15 1SF UK
}

\author{
Paul Ormerod \\ Volterra Partners \\ and \\ University of Durham, UK
}

\begin{abstract}
Rosewell and Ormerod have collaborated for over a decade in Volterra Partners, building models using complexity principles for clients in the public and private sectors. We present examples of agent based models commissioned by policy makers and used as inputs into the decision making process. We discuss problems which arise within both public and private sectors when a complex modelling approach is proposed. For example, the standard approach to policy analysis, that of economics, has the advantage in that it often purports to give the right answer. Complex systems modelling in contrast emphasises uncertainty of outcome. The paper describes the way in which policy makers describe and identify problems, how they can be engaged, how they can 'buy in' to the results of a model, how to involve the decision maker in the validation of the model. These points are illustrated from actual models which have been built in practice.
\end{abstract}

\section{INTRODUCTION}

The policy process is a problem solving one. Policy makers need to produce convincing answers to a problem which seem to give reasonable certainty that a proposed policy will work. Such problem solving requires an intellectual framework which makes sense to both the policy analyst and the decision maker.

Over the last half century or so, this framework has been based on a particular paradigm in which models are deterministic, and where marginal rather than large changes are the main focus of the analytical process.

This framework is the framework of economics. The intellectual input into the process of both social and economic policy making in the West continues to be dominated by this discipline. This is not to say that other social sciences do not have an input, but the influence of economics is pervasive.

There are two aspects to this. First, the emphasis in policy is on the role of incentives, especially marginal ones, the fundamental building block of economics. Agents - decision makers - respond and alter their behaviour when the set of incentives which they face changes. So the emphasis is on taxes, subsidies, and the impact of regulation on incentives.

The second aspect is the equilibrium framework in which economists typically think. Even if a system is not at equilibrium at a given moment, the basic tendency of the economy, according to this view, is to move back towards equilibrium. So there is a great deal of policy which is based on the concept of 'market failure', that there are imperfections in information or other constraints on the behaviour of agents which prevent 'the market' from operating as it should and restoring equilibrium. In the context, say, of unemployment, for decades the idea has persisted within economics that many unemployed people 


\section{Rosewell and Ormerod}

are simply choosing leisure rather than work, and a potential solution is to cut the level of benefits to restore equilibrium in the labour market. Overall, this is a framework in which the world can be portrayed as deterministic.

The combination of marginal analysis and an equilibrium framework permits the derivation of optimising and optimal criteria. It allows policy makers to conclude that they can design a better world in which everyone can be better off either financially or in welfare terms. This is therefore a very comforting framework which will be hard to abandon unless it is either clearly shown to be misleading or can be replaced by something more effective. It explains why long established results can be set aside or ignored because they do not help decision makers come to a conclusion. For example, Lipsey and Lancaster (1956) showed over fifty years ago that a policy change that makes one market more efficient does not necessarily improve the overall efficiency or welfare of the system. This result is both well known and ignored in practice.

In the real world decisions have to be made, by businesses, governments, and other organisations. They will rest on the available evidence and the available decision frameworks, but tacit and instinctive positions are just as likely to be important as a careful weighing up of all options. These are decisions based on what Kahneman (2012) has called System 1 thinking. Agent based models operating on complexity principles are a much better framework in which to capture this important concept. The timetable for a full and comprehensive academic analysis is hardly ever available. On the other hand an analysis that would fit the needs of a project is not necessarily worse than a full study. As in other areas it is fitness for purpose that matters.

It is crucial in the decision process that analysis remains relevant to the concerns of the policy makers. The extent of added complexity and variety of behaviour must be carefully considered. In most jurisdictions there is a developed set of rules for defining and analysing policy questions. As a policy maker once said to one of the authors, we have been doing it this way for thirty years, so how can it be wrong?

It is therefore essential for modellers to understand that innovation in policy analysis usually arises from the need to support a policy preference or choice. Decision makers themselves are not in general interested in the science which underlies the modelling.

\section{COMPLEXITY, AGENT BASED MODELS AND THE INCUMBENT PARADIGM}

Agent based models will generate a range of potential outcomes for any policy which creates uncertainty for the policy maker. This applies across all ranges of policy problems - from the impact of interest rates changes to deciding taxation impacts.

This paper examines a range of policy problems and the kind of frameworks which can address the issues potentially more effectively than deterministic or marginal ones. While a less deterministic framework allows us to consider a wider range of outcomes and policy risks, it also leads to new questions of validation and acceptance. These are as important as establishing new frameworks in the first place. Many existing models are 'black boxes' which are hard to explain or to use. But they are nonetheless familiar boxes. A new approach will require new rules of engagement. We address these very briefly in the later parts of the paper.

In a practical context, it is essential for the agent-based, complex systems modelling community to appreciate the power of the incumbent discipline: economics. Keynes wrote as long ago as the 1930s that 'The ideas of economists...., both when they are right and when they are wrong, are more powerful than is commonly understood. Indeed, the world is ruled by little else. Practical men, who believe themselves to be quite exempt from any intellectual influences, are usually the slaves of some defunct economist'. This remains true today.

In many ways, economics has authority simply because it has authority, and has had authority for decades. Decision makers, who in general are not experts in any particular discipline, are often predis- 


\section{Rosewell and Ormerod}

posed to consider the recommendations based on economic models favourably. They are tried and trusted. Further, economists have the advantage in that they often purport to give the answer.

Economics, over the course of a century or more, has honed and refined its methodological and epistemological approaches to the analysis of practical questions. This does not mean that it correct. But because of this process within the subject, there is much more agreement amongst economists than is commonly supposed. So, for example, different teams of economists might disagree on the impact of, say, a road pricing proposal. But they will agree on how conceptually the problem should be approached.

The issues of methodology and epistemology are not mere ivory tower questions. Addressing such issues is a necessary condition for the use of agent-based, complex systems models to become more widespread in the policy process. Our models are different from those of economics. But we need to articulate and explain these principles more clearly, both to show the strengths of the approach and to make clear the disadvantages from the perspective of the decision maker.

The authors of this paper have collaborated for over a decade in Volterra Partners, building models using complexity principles for clients in both the public and private sectors. Both have direct experience of policy making, Rosewell in particular. For example, she worked directly with the UK finance minister in the 1990s and has been a board member of several major companies over the past decade. She has been the chief economic adviser to the Mayor of London for eight years.

We consider here some key issues in agent based modelling, and illustrate them with examples of models which we have been paid to build. Models which have been used as inputs into the decision making process.

\section{CHALLENGES OF INTRODUCING AGENT BASED MODELS INTO THE POLICY PROCESS}

As we noted in the Introduction, a key reason why innovative modelling approaches are demanded by policy makers is because conventional methods are not providing an adequate level of support for a policy preference or choice.

The complexity modelling community in general, in our opinion, fails to understand this point, and appears to believe that simply doing superior science will itself lead the complex systems approach to be adopted. This is unlikely. The dominant paradigm is very strong. The agent based/complex systems modelling approach, to become more widely adopted, must understand the needs of policy makers. Of course, once we have got beyond the critical mass, once a sufficient number of models of this kind have been successful and useful to policy makers, then network theory itself tells us that the approach is then likely to percolate rapidly and become the new dominant paradigm! But we are some distance away from this as yet.

\subsection{Prediction and Explanation: Employment in London}

Sometimes, the innovation may in scientific terms be rather trivial. For example, the Greater London Authority is legally obliged to publish forecasts for employment in London, both in total and in 12 industrial sectors, over a 25 year time horizon. The forecasts can be made subject to scrutiny at a public inquiry, when the entire London Plan, of which these forecasts are a small but important part, is examined.

The task had been carried out using conventional, large scale econometric models. The problem was that it was hard to understand, given the fact that these models can be very complicated (as opposed to being simple but complex). The policy makers who face cross-examination at the inquiry into the Plan needed to be able to understand and explain the forecasts. We therefore took as a basis the estimated long-term sustainable growth rate of output published by the Treasury, the UK Finance Ministry. We fitted non-linear trend terms to productivity growth, and used the identity that productivity equals output divided by employment to make the projections. The policy makers could understand this process (and, as it happens, the trend forecasts have been remarkably accurate, although they do not of course capture the short term fluctuations around the trend). 


\section{Rosewell and Ormerod}

The simple example above illustrates the distinction. The model has zero explanatory power, but is a useful forecasting device. In much policy making the line is blurred between explanation and prediction. Most policy questions involve asking how a future world will be different if a particular policy is adopted. This actually involves three key propositions:

Can I explain the current position in this policy area?

Can I be confident how it will evolve if left alone?

Can I know how it will change if parameters change?

These propositions are theoretically distinct. For millennia there have been models which have predicted the movements of planets and stars fairly accurately, but which explained them in terms of mystery and religious forces. Macro-economic models used to explain the past evolution of the economy will link outputs such as investment and consumer spending to other elements of the model and finally to variables outside the model - such as population. So what will drive the future evolution is the behaviour of these exogenous variables, precisely what the forecaster knows least about.

Using any model to ask the 'what if' question requires a good understanding of what is being held constant. A model can be run with, for example, a different oil price. Is it reasonable to leave all else unchanged? What reactions might there be? Would other behaviours change? Cross section models, such as those used in transport or to study input output relationships, are very risky is used to examine large changes. And since they are expensive to build and maintain, this is what they are used for. Yet a large change in transport availability will probably change other relationships too. A large investment on a particular site will encourage other activities, and may well force or encourage innovation which will change supply chain relationships.

Economists are beloved of the assumption of 'ceteris paribus' - other things being equal. Too often they do not stop to consider what other things will not be equal in a particular case. The advantage of agent based modelling is that it does force the analyst to consider such questions. Which behavioural rules are relevant and which agents affect which others become highly charged questions which need considerable thought. To hold all else equal is both a lazy way out and requires making other, albeit implicit, assumptions.

\subsection{Crossrail}

An important example of agent based, complexity modelling in which we have been engaged was in building the case for Crossrail, a major transport infrastructure project crossing London. Crossrail is now being constructed.

The Crossrail project had a long gestation before it was finally agreed and financed in 2009. Although business, transport planners and local government all agreed it was essential from at least the 1980s, the size and cost of the project frightened central government. Standard evaluation methodologies in use in the UK gave it a positive benefit cost ratio but with not as much margin as financial officials were prepared to accept.

New analysis needed to be brought to bear. Appreciation of the feedbacks inherent in large and long term transport projects were a necessary addition to the evaluation mechanisms and made it possible to evaluate quite differently the financial benefits of the scheme as well as adding to the theoretical concepts. This concept added into the evaluation the idea of agglomeration - the higher productivity associated with co-location and the way in which transport could be a constraint of this growth and its associated financial benefits.

The presentation of these arguments in simple and compelling ways assisted the business and local government community to create an economic case for the railway which could not be denied. Even so, the development of the case and the associated permissions took from 2002 to 2009, and the tunnelling got started in 2012 . 


\section{Rosewell and Ormerod}

\subsection{Svenska Handelsbanken}

A quite different example is the agent based model we built for Svenska Handelsbanken, Sweden's largest bank.

In the early 1990s, Sweden experienced a recession which was almost as bad as that of the Great Depression period of the 1930s. Defaults on corporate loans rose sharply as a result. The default rate of SH was, however, considerably lower than that of its main competitors.

The bank wanted to know, essentially, whether this was due to pure good fortune given that the bank was much less exposed in the sectors here defaults were particularly high, or whether it was due to their own process of granting and monitoring of corporate loans.

The system at SH had evolved over many years. In contrast to the very centralised, tick-box driven approach of most banks, at SH the officer at the branch level is able to exercise considerable judgement on both the granting and the monitoring of corporate loans. A set of guidelines does exist, but they are not rigid. The office is informed in part by his or her private information and opinion. But an additional important influence is the informal network across the whole of the bank through which knowledge, both explicit and tacit, about an industry, a firm or even the individual asking for the loan, is exchanged.

The bank not only wanted to know the answer for itself, but it was under pressure from the regulators to adopt a process more in keeping with the industry standard, a much more centralised approach with little scope for individual judgement.

We developed an agent based model for the processes of granting and monitoring corporate loans. The structure of the network was approximated using the evidence from a survey designed with the assistance of the bank. The average path length of the network was low, indicating that knowledge flowed very readily across it. We ran simulations of the model with both the approximation to the actual network and with networks with distinctly higher path lengths, even removing the network altogether in one set of solutions. The conclusion was that the network, and the efficiency with which knowledge could be transmitted across it, was an important reason for SH's good comparative performance in the early 1990s. By coincidence, we presented these findings to board members in the summer of 2008. In the recession which followed almost immediately, SH once again had a good comparative performance on corporate loan defaults.

The model describes a process of granting and monitoring corporate loans which is completely different from that of the conventional, top-down, tick-process. It identifies that a key reason for SH's success is precisely this process, and in particular the use which this makes of informal, tacit knowledge held at all levels of the bank. The results suggest that this process should be adopted much more widely by financial institutions.

\subsection{British Telecom}

A practical example was a model we built for British Telecom some ten years ago, who were involved in discussions with the regulator on their market share of the landline market in the UK. BT had been a monopoly supplier, and the company continued to maintain a large market share despite the opening upon of the market to new entrants and hence to competition. On standard criteria, the market share was anticompetitive. The company needed to be able to show that their large market share did not constitute a prima facie case of them being anti-competitive, which orthodox economic models did.

Our model focused on the process by which new entrants came into a market opened up to competition for the first time. The monopolist provides a combination of price and quality [p, q], which are, respectively, high and poor. A firm is chosen to enter with a random combination of [p, q], with the proviso that both are better than that initially provided by the monopolist. Not all consumers will be aware of this new entrant, but those who are have the opportunity to switch. There are rules specifying when they will do this, how the monopolist can respond to the newly offered [p, q], and so on. For example, in subse- 


\section{Rosewell and Ormerod}

quent periods, firms enter the market depending upon their assessment of potential profit, which in turn depends upon the $[\mathrm{p}, \mathrm{q}]$ combination which has become established at that point in time.

In general, the market eventually contains an indeterminate number of producers, each of which supplies the product either at or close to the minimum price which is both technologically feasible and enables a normal rate of profit to be made. In other words, we begin with a monopoly and end with the perfectly competitive market of standard economic theory.

However, judged on the conventional criterion of the distribution of market shares, the market structure which emerges is, in general, anti-competitive. As the outcome on market price shows, the model is highly competitive in any meaningful sense of the word. The market price which emerges, given the number of firms in the market in any particular solution of the model, is in general lower than that implied by the equilibrium Cournot price, substantially so when the number of firms is small. The model further differs from conventional theory in that, across a large number of individual solutions of the mod$\mathrm{el}$, there is no connection between the market price and the number of firms.

Conventional theory does not really provide an account of the process by which the market structure evolves. This model does. Further, although the model in general converges on an outcome which is similar to that of the conventional concept of perfect competition, the policy implications are completely different. It is the process of competition which ensures this result, independent of the number of firms which either try to enter or which survive.

\subsection{Innovation in the Greater Manchester region}

The local authorities in this region, with a population of some 2.5 million, wanted to understand how to encourage the spread of innovation in industries across the region. Conventional economics told them very little about this process. As part of a wider study, the Manchester Independent Economic Review, we were asked to provide policy guidelines on this matter.

This model looks at innovation as a dynamic and disequilibrating process which is dependent on the ability of innovators to pass on their innovation. A detailed description is in Ormerod and Rosewell (2011)

The model takes an initial innovation to be exogenous and it is taken up by one agent/organisation at the outset. The characteristics of the agents are governed by their willingness to innovate, their desire to keep innovation to themselves, and their willingness to communicate with others. We define two different methods by which innovation may be passed on via the network linkages. The first is a direct relationship between two partners, while the second is a group relationship.

First, an organisation with an innovation will provide it to another firm only if its level of secrecy, or the propensity of a firm to try to retain the benefits of its innovations, is less than the absorptive capacity, or the degree to which a firm actively engages in activities which enable it to identify and adopt new innovations, of the firms it is linked with. This method of adopting an innovation represents a mutual relationship or exchange between firms and implies a degree of trust or collaboration. It is probable that this relationship is more likely to exist with customers, suppliers or third parties than with competitors.

The second method for spreading an innovation we describe as a copying behaviour. Here if a firm looks at the spectrum of organisations to which it is linked and finds that the proportion that have adopted an innovation is higher than their own personal threshold, they will mimic their behaviour and adopt the innovation

The network behaviour was not set a priori. We were able to calibrate the network across which any innovation percolates to the actual networks in a survey.

This model offers a way of thinking about innovation based on dissemination across a network where the behavioural rules of innovating organisations also have a bearing on the outcome. It enabled us to analyse the potential for cascades of innovation and features likely to limit such potential. The model shows that the distribution of parameters across groups of agents matters as well as averages. The ability to calibrate these distributions to survey results in a region of the UK enables us to investigate the importance of the distributions as well as the average values of the parameters. 


\section{Rosewell and Ormerod}

The results showed that the ability to distinguish between a successful, global, cascade of innovation at the outset is very limited. Whether a cascade emerges or not is very difficult at the outset. We can see that industry surveys with similar results for innovation behaviour and attitudes can nonetheless produce very variable outcomes. Moreover, initial success cannot predict the final outcome.

Classically, policy has concentrated on identifying innovation that ought to be supported, and on creating sector support groups. In the UK, the latest policy initiative has been the establishment of NESTA (National Endowment for Science, Technology and the Arts). A recent pronouncement suggested setting up new sector groups, to look at different ways innovation takes place in 'non-traditional' sectors. How this is likely to help change the parameters of the kinds of behaviour which generate innovation take-up is not at all clear.

However, the models do suggest that there are ways to help maximise the likelihood of innovation spreading. The model shows that:

- The willingness to exchange innovation is a major driver

- Well-connected but not too dense networks help

- A willingness to copy others helps.

Policy can help create networks by events and the support of the widest possible networks. Note that these need to be more broadly focused that on just one sector. Policy to support the willingness to absorb innovation is much more difficult. The policy instinct is to provide grants or tax breaks. However, there is no guarantee these would support the sort of innovation that organisations can readily use, which may be hard to identify in policy terms.

The conclusion can only be that a continual policy of supporting test and try which does not worry too much about an ex ante analysis of the potential for success is the only option

\section{METHODOLOGICAL ISSUES}

As mentioned in the Introduction, these are not abstract, ivory tower matters. Even if policy makers are inclined to commission an innovative approach, it may still face opposition from the more conventional modellers in the bureaucracy. Many of their objections will be, in essence, methodological, and the complex systems modelling community is not yet able to draw on a widely shared vision to counter these objections. In our view, much more effort needs to be put into methodological aspects of complex systems modelling. We note here a few key issues.

\subsection{Validation}

A crucial issue relates to the validation of agent-based models. We discuss this at greater length in Ormerod and Rosewell (2009). A criticism frequently encountered from economists in organisations is along the lines 'this is all very well, but how do you know the model is correct? Surely there are many sets of rules which would give similar results?' Our response to the latter is usually to tell them that if it is so easy, they should go away and produce some other sets of rules, which buys silence, if not agreement.

But they have a point. Econometrics for example, for all its limitations, has a well developed methodological process of model validation. It has inherent limitations, in that a regression is simply planefitting in $n$ dimensions and is not readily generalisable. Further, in practice most applied econometricians violate the basic precepts of statistical theory. In general, the power of statistical tests is known if a hypothesis is formulated and then confronted with the data. What happens in practice is that if a specification fails a test, the econometrician will re-specify until he or she gets a 'model' which passes the test. But by then the power of the test is theoretically unknown, although the strong presumption is that it is much weaker than that which would obtain if the precepts of classical statistical theory had been followed. However, econometricians believe that they have such a procedure, which informs them as to whether the model has been validated or not. 


\section{Rosewell and Ormerod}

Agent-based modelling lacks generally agreed, basic tests which would indicate whether or not a model is over-fitted. A concept such as the Akaike Information Criterion to penalise over-fitting is an obvious example, for which there is no obvious parallel in the world of complexity and agent-based modelling

Economics, too, has a very clear view as to what and what is not, in economic terms, a valid way of analyzing and thinking about the world. We have already discussed above the power of this paradigm. There is much more agreement amongst economists than is generally appreciated. Mainstream practitioners agree on what does and what does not constitute, in their terms, a scientific modelling approach.

\subsection{Imperfect Information or Imperfect Knowledge?}

There is a key distinction to be made between the concept of imperfect information and that of imperfect knowledge. Imperfect information is associated with the concept of bounded rationality, and developed within economics by Akerlof (1970) and Stiglitz (1977). Bounded rationality in this sense implies that the decision making process follows the same rules as when perfect information is available but includes an assessment of the costs of acquiring information. Information will exist but if its capacity to improve a decision is less than its cost it will be ignored. Equally some agents may have better access to information than others and are able to create false market signals.

Imperfect knowledge is different from this and can be regarded as being in the tradition of Hayek and Simon. In many situations, there are inherent limits to knowledge, which no amount of additional information can overcome (Hayek, 1974 for example). The same concept underpins Simon's seminal 1955 article on behavioural economics. Economists now interpret his phrase 'satisficing' to mean that agents look at a limited number of alternatives until they find one that is satisfactory, judging that a superior one might very well be found, but that the time and effort involved in the discovery of it would outweigh the additional benefits, in other words in the context of imperfect information. On the contrary, Simon argued that, in many situations, all that we are able to do is to find a satisfactory choice or make a satisfactory decision. Even ex post, the optimal choice or decision cannot be discovered.

In contrast to mainstream economics, complex systems modelling stresses the role of imperfect knowledge in human affairs. Imperfect knowledge can derive from both inadequate frameworks for models and from an inadequate application of models. One way to develop the application of our models is to ensure that stochastic elements are used to capture variations of behaviour outside the core model. The stochastic terms reflect the situation of imperfect knowledge in which we operate. We can identify at least four sources of imperfect knowledge, of uncertainty in the Knightian sense.

These are uncertainty about the starting point (the initial conditions); the order in which agents take decisions; the network which connects them and the behavioural rules that they follow. The first of these is not just about the accuracy of data. Depending on the starting point, a system can follow a very different path, either towards or away from an equilibrium. In many cases, only a small change in the starting point can make a big difference.

The other three elements all describe potential ways in which feedbacks can operate and behaviours diverge from the standard view of how decisions are taken.

\subsection{Dynamics}

A consequence of the equilibrium paradigm is that much analysis compares a current situation (or a forecast one) as an equilibrium with another potential equilibrium after a policy change, an investment, or a 'shock'. This has been particularly prevalent in macro-economics, which finds it much easier to compare equilibrium outcomes when changes have worked through.

For example, the mainstream paradigm in academic macroeconomics is DSGE, or dynamic stochastic general equilibrium models to give the full description (for example, Smets and Wouter 2003, Tovar 2009). There are many critiques of such models, and two from an agent-based complexity perspective are Farmer et al. (2012) and Ormerod and Helbing (2012). 


\section{Rosewell and Ormerod}

The reason that such models seem to more suitable for policy simulation is that their equilibrium properties guarantee that results can be produced. This is however putting the cart before the horse as it certainly does not guarantee that results are realistic.

Another example is the use of cost benefit analysis. In principle the idea that we make a decision based on the balance between costs and benefits is an eminently sensible one. Who could disagree with this? The questions arise when considering how to value them, especially in the case of the benefits of a proposal. A recent example of the difficulties of comparing future benefits with current costs arose in the context of the Stern report (2006) into dealing with climate change. His calculations took a very low discount rate so future generations had a high value, while also forecasting that economic growth would continue in the world economy. The result, as several economists pointed out (for example Nordhaus 2007), was to impose costs on poor people now to benefit rich people several generations hence, while also assuming that none of these future people would act to avoid the negative consequences, by moving away from flood plains for example.

The dynamics of feedbacks can also make a potential difference to policy outcomes. The concept of agglomeration goes back to Alfred Marshall in the 1890s and his description of how growing locations could create more effective labour markets, spillover effects and innovation. The concept is essentially dynamic as each addition to the central area creates a further benefit not just to those joining the agglomeration but to those already there. There is no sensible answer to the question of the equilibrium size of an agglomeration.

\subsection{Parsimonious or Large Models?}

This is a major issue on which there is already a considerable literature, and the length of the discussion here does not reflect its inherent importance. Our concern is to set the debate in the context of the need to deal with the phalanx of mainstream economic opinion in persuading decision makers that complexitybased agent based models should be used to help inform decisions.

We obviously cannot say that the absolute size of a parsimonious model has to lie below a certain number of parameters, this will be context dependent. As Dibble (2006) states: 'parsimonious modelling means selecting the simplest possible model capable of generating a phenomenon of interest'.

By 'parsimonious' we do not necessarily mean that the model is only populated by a small number of agents. Advances in computing capacity enable us to include many agents. But the presumption is that a parsimonious model will contain a fairly small number of parameters. An important advantage of this, given the time and resource constraints under which models have to be built in many practical decision making contexts, is that a model can be developed within the required timeframe. Further, we can explore its properties more easily than is the case with larger models.

There is, however, often an important tension in any practical context. Decision makers often believe that their particular problem can only be understood by knowing a great deal about the issue, and by taking into account a large number of factors. This is particularly the case with what we might term senior middle management, people who have spent their working lives in the industry or policy area and who will probably never make the board themselves. At the highest level, there is often much more awareness of the need to abstract key issues. Nevertheless, in most consultative processes where knowledge about a particular problem is extracted, the tendency for non-model builders is usually to want to include more detail rather than less.

\section{CONCLUSION - ACCEPTANCE AND RELEVANCE}

This paper has looked at a number of examples of models used in the policy making process. They differ in their scale and scope and in the techniques they have used as well as the problems they address. In each 


\section{Rosewell and Ormerod}

case, the new complex systems approach has arisen to address a problem that the standard model appeared to give an answer that at least some policy makers thought was insufficient, wrong, or hard to understand. This illustrates that in making policy, there is a need for a shared set of assumptions and that judgements are an important starting point. It is impossible to set up every problem from the ground up, so new approaches must build on those which already exist.

Policy makers are impatient. The current paradigm is one where changes can be assessed in a common framework based on the principles of agents which maximise and which learn effectively. Prima facie, this appears to make sense. It produces clear answers and can be embedded in the policy choice framework. It is challenged when the answers produced are themselves challenged.

If a forecast does not make sense, or an investment which appears to offer good value is not supported, or the dynamics of a real competitive situation are ignored, then a new approach becomes attractive. It is crucial to remember that if the standard approach produces the desired outcome, then there will be no desire to develop a stronger approach.

In practice, small changes can be so small that agents cannot react to that which is too small to see, while large changes may well change the parameters of their choices. Learning in a changing world is hard and so any form of optimisation is beyond most agents' scope. Many policy makers would recognise such realities in a description. Nonetheless an approach which recognises this will only get traction in the real world if it offers a preferred outcome at not too high a cost either in time or money. Policy is not a theory of everything.

Developing a new and shared set of rules which allows us to approach such realities must be recognised as a hard problem which we are only just beginning to address. How a question is defined, what sort of model should be used to address it, the standards of validation, and what is being held constant are all hard questions to address.

Nevertheless, progress is being made. Approaches to policy problems which recognise variants on agent behaviour, or the importance of dynamics, or feedbacks are increasingly being used. The agent based modelling community needs to recognise these steps and work to bed them in and strengthen them with an evolving set of rules of engagement, approaches to validation and tests of relevance.

\section{ACKNOWLEDGMENTS}

The authors acknowledge the support of the EU Co-ordinated Action Non-Equilibrium Social Science (NESS), part of the Global Systems Science initiative, and of the FP7 ICT project Open Collaboration for Policy Modelling (OCOPOMO).

\section{REFERENCES}

Akerlof, G.A., 1970, 'The Market for "Lemons": Quality Uncertainty and the Market Mechanism', Quarterly Journal of Economics, 84, 488-500

Dibble, C., 2006, 'Computational Laboratories for Spatial Agent-based Models, in L. Tesfatsion and K.L. Judd, eds., Handbook of Computational Economics: Agent-Based Computational Economics, vol II, Elsevier

Farmer J.D., Gallegati M., Hommes C., Kirman A.P., Ormerod P., Cincotti S., Sanchez. A. and Helbing, D., 2012, forthcoming, 'A complex systems approach to constructing better models for managing financial markets and the economy', European Physics Journal

Hayek, F.A., 1974, 'The Pretence of Knowledge', Nobel Prize lecture, (http://www.nobelprize.org/nobel_prizes/economics/laureates/1974/hayek-lecture.html

Kahneman, D., 2012, Thinking, Fast and Slow, Penguin

Lipsey, R.G. and Lancaster, K., 1956-1957, 'The General Theory of Second Best', Review of Economic Studies, 24(1), 11-32

Marshall, A., 1890, Principles of Economics, Macmillan, London 


\section{Rosewell and Ormerod}

Nordhaus, W., 2007, 'Critical assumptions in the Stern Review on Climate Change', Science, 317, 201202

Ormerod, P. and Helbing, D., 2012, forthcoming, 'Back to the drawing board for macroeconomics' in the Proceedings of the Bank of England/UK Government Economic Service Workshop on: What Should Graduate Economists Know?, February 2012

Ormerod, P. And Rosewell, B., 2011, Network models of innovation processes and policy implications, in Antonelli, C., ed., Handbook on the Economic Complexity of Technological Change, Edward Elgar

Ormerod, P. and Rosewell, B., 2009, 'Validation and Verification of Agent-Based Models in the Social Sciences', in Squazzoni, F. ed., Epistemological Aspects of Computer Simulation in the Social Sciences - Lecture Notes in Computer Science, Springer Berlin / Heidelberg, 5466, 130-140, doi: 10.1007/978-3-642-01109-2 _ 10

Simon, H.A., 1955, 'A Behavioral Model of Rational Choice', Quarterly Journal of Economics, 69, 99118

Smets, F. and Wouters, R., 2003, 'An estimated dynamic stochastic general equilibrium model of the euro area', Journal of the European Economic Association, 5, 1123-1175

Stern, N., 2006, Stern Review on the Economics of Climate Change, HM Treasury, London

Stiglitz, J. and Salop,S., 1977, 'Bargains and Ripoffs: A Model of Monopolistically Competitive Price Dispersion', Review of Economic Studies, 44, 493-510

Tovar, C.E., 2009, 'DSGE models and central banks', Economics E-Journal, 3, http://dx.doi.org/10.5018/economics-ejournal.ja.2009-16

\section{AUTHOR BIOGRAHIES}

BRIDGET ROSEWELL studied Politics and Economics at Oxford University, where she also taught Economics for eight years. Subsequently she has pursued policy and business interests, establishing two successful economic consultancies and making the case for a number of large infrastructure projects. She is now also a non-executive director for a large infrastructure business and a bank. Her email address is brosewell@volterra.co.uk.

PAUL ORMEROD studied economics at Cambridge University and is an economist, best-selling author of Death of Economics, Butterfly Economics, Why Most Things Fail and Positive Linking. He is a partner in Volterra Partners LLP, London. His research interests are networks and complex systems. He has an honorary doctorate from Durham University, UK. His email address is pormerod@volterra.co.uk. 